\title{
Correction to: Unravelling the variability and causes of smallholder maize yield gaps in Ethiopia
}

\author{
Banchayehu Tessema Assefa $^{1}$ • Jordan Chamberlin ${ }^{2}$ • Pytrik Reidsma ${ }^{1}$ • João Vasco Silva ${ }^{1,3}$ • Martin K. van Ittersum ${ }^{1}$
}

Published online: 4 January 2020

(C) International Society for Plant Pathology and Springer Nature B.V. 2020

Correction to: Food Security.

https://doi.org/10.1007/s12571-019-00981-4

The original version of this article unfortunately contained the following errors.

(1) Title of co-author Pytrik Reidsma should be Associate Professor instead of Assistant Professor.

(2) In Fig. 6, the explanations in the legend are switched. The corrected figure is shown here.

The online version of the original article can be found at https://doi.org/ 10.1007/s12571-019-00981-4

Banchayehu Tessema Assefa

banchayehu.assefa@wur.nl

1 Plant Production Systems, Wageningen University,

6700 Wageningen, AK, Netherlands

2 International Maize and Wheat Improvement Center (CIMMYT),

Nairobi, Kenya

3 Centre for Crop Systems Analysis, Wageningen University,

6700 Wageningen, AK, Netherlands 


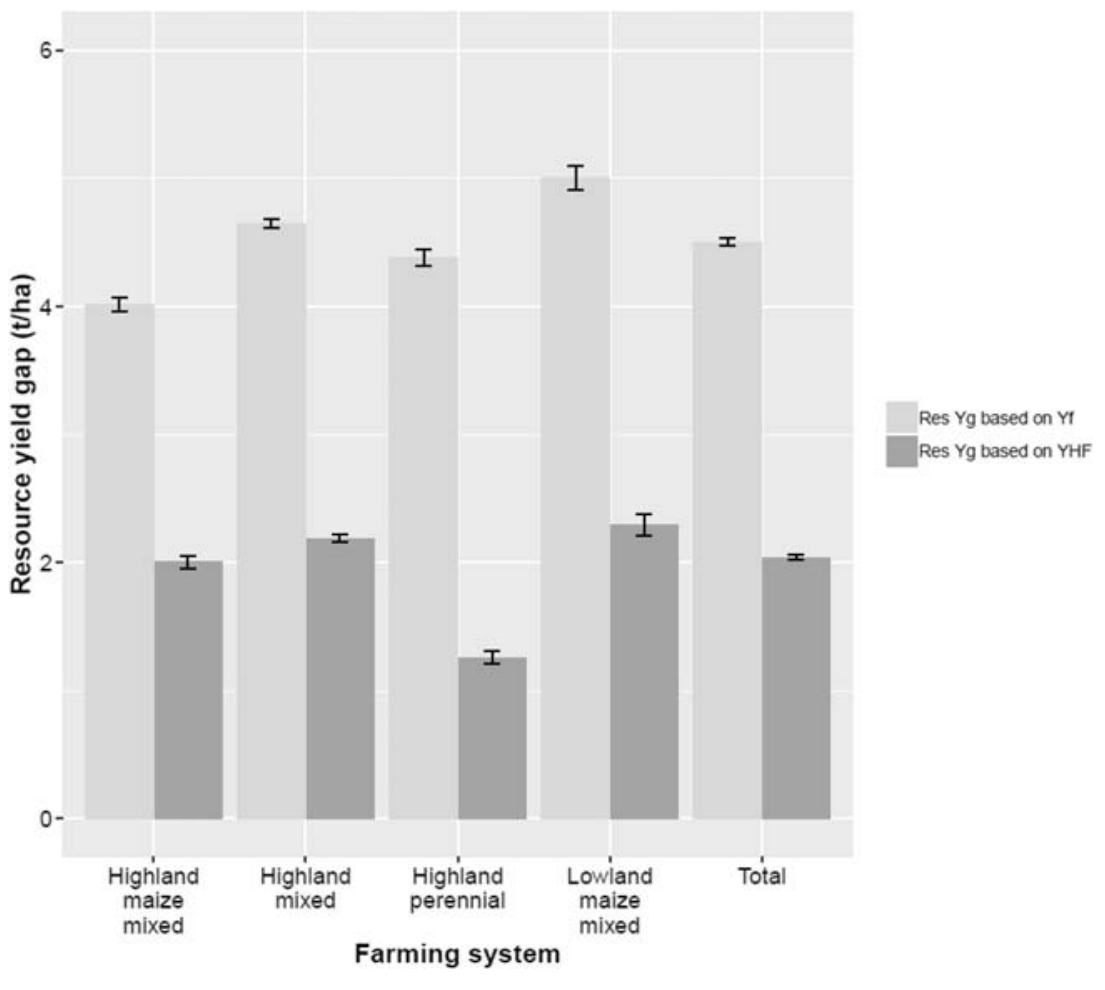

